\title{
Persistent Organic Pollutants in Serum and Several Different Fat Compartments in Humans
}

\author{
George W. Yu, ${ }^{1}$ John Laseter, ${ }^{2}$ and Charles Mylander ${ }^{3}$ \\ ${ }^{1}$ George Washington University Medical Center, Washington, DC 20037, USA \\ ${ }^{2}$ Accuchem Laboratories, Richardson, TX 75081, USA \\ ${ }^{3}$ Department of Statistics, Naval Academy, Annapolis, MD 21401, USA
}

Correspondence should be addressed to George W. Yu, george.yu8@gmail.com

Received 19 January 2011; Accepted 10 February 2011

Academic Editor: David O. Carpenter

Copyright ( $) 2011$ George W. Yu et al. This is an open access article distributed under the Creative Commons Attribution License, which permits unrestricted use, distribution, and reproduction in any medium, provided the original work is properly cited.

\begin{abstract}
Background. Chemicals that store in lipid-rich compartments have the potential for long-term disruption of metabolic and endocrine processes. Given the evidence that persistent organic pollutants (POPs) also alter systemic metabolic, endocrine, and immune system functions, it follows that elevated chemical concentrations in intra-abdominal fat may alter function, through local chemical signaling, of visceral organs. Despite this potential, there has been little study defining POP concentrations in live human intra-abdominal fat. It is at present uncertain whether POPs distribute equally to all fat compartments, including fat in serum. Methods. Seven human subjects scheduled for elective surgery for benign lesions or cancer provided consent for removal of samples of subcutaneous and intra-abdominal fat and/or cancerous tissue. These samples were analyzed for 22 chlorinated pesticides and 10 polychlorinated biphenyl (PCB) congeners by GC/ECD plus GC/MS. Results. In only two subjects were the patterns and relative concentrations of PCBs and pesticides about the same in all fat compartments. In the other subjects, there were major differences in levels in subcutaneous as compared to other compartments, but with some higher and some lower. While the pattern of PCBs in the various compartments matched that of the pesticides in some, it was opposite in others. Interpretation. These results demonstrate a complicated distribution of PCB congeners and pesticides in various lipid compartments. The difference may reflect various $\mathrm{K}_{\mathrm{ow}} \mathrm{s}$, different rates of metabolism, and/or different lengths of exposure. But the results suggest that contaminant levels in serum or even subcutaneous fat do not necessarily indicate concentrations and patterns in other kinds of adipose tissue.
\end{abstract}

\section{Introduction}

While adipose tissue has in the past been viewed as a depot involved in passive storage of energy, it is increasingly clear that it is in fact a highly active tissue. It is an endocrine organ, secreting various cytokines and regulating metabolism of other organs. Adipose tissue affects not only body weight, but also insulin sensitivity, atherogenesis, blood pressure, and other physiological functions [1]. The body has several depots of white adipose tissue, of which the major two categories are subcutaneous and visceral, although visceral fat can be divided into subcategories of intraperitoneal, retroperitoneal, and pelvic. Most studies have shown relatively little difference in the fatty acid composition of the various fat stores including fat in serum [2]. However, there is suggestion that this may not be the case in obese individuals [3] and Kishino et al. [4] reported that visceral fat thickness was positively correlated to levels of palmitic and saturate fatty acids in serum, but negatively correlated with levels of linoleic and polyunsaturated fatty acids. There is a growing body of evidence that many of the cytokines and growth factors have depot-specific distribution in human adipose tissue [5-7]. It is known that visceral fat correlates better with the development of insulin insensitivity and the metabolic syndrome than does subcutaneous fat, and this may be related to the demonstrations that there is greater glucose uptake [8] and insulin metabolism [9] in visceral fat.

Persistent organic pollutants (POPs) are highly lipophilic chemicals that bioaccumulate in animal and human fats [1]. POPs includes chemicals such as dioxins/furans, polychlorinated biphenyls (PCBs), chlorinated pesticides, brominated 


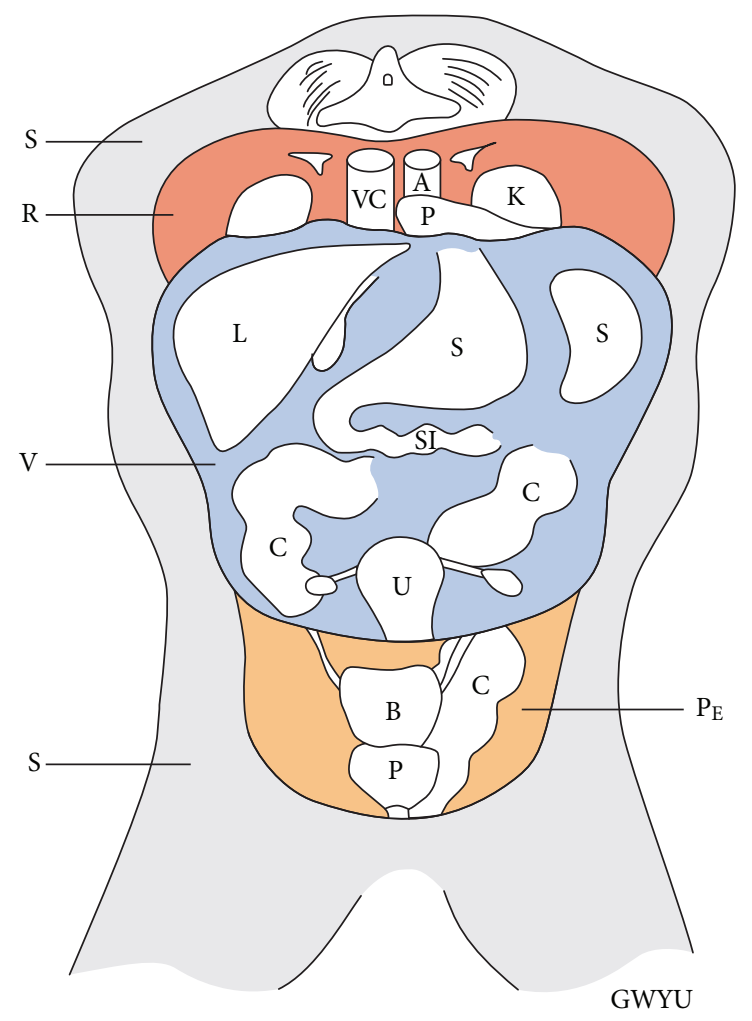

S: subcutaneous
V: visceral
$\mathrm{R}$ : retroperitoneal
$\mathrm{P}_{\mathrm{E}}$ : pelvic

Figure 1: Fat components. Organs are identified as follows: VC: vena cava; A: aorta; P: pancreas; K: kidney; L: liver; S: stomach and spleen; C: colon; U: uterus; B: bladder; P: prostate.

flame retardants, and perfluorinated compounds. Because of chlorine, bromine, or fluoride groups on the hydrocarbon rings or chains, these substances are resistant to degradation both in the environment and in the human body. The half-lives of substances such as DDE, the major metabolite of DDT, and some PCB congeners are of the order of 5-10 years, and because of their presence in almost all animal fat consumed with the diet, the concentrations in the human body tend to increase with age because rates of intake exceed those of metabolism and excretion [10]. While the manufacture and use of most of these chemicals has been prohibited in the US through the Toxic Substances Control Act of 1976 and their manufacture and use on a global scale is outlawed by the Stockholm Convention of the United Nations which entered into force in 2004, these toxic chemicals remain present in the bodies of most humans.

POPs are toxic to human health, being probable human carcinogens, having immunosuppressive activity, causing neurotoxicity, increasing risk of diabetes, cardiovascular disease, and hypertension, and being endocrine disruptive chemicals $[11,12]$. Different POPs often have somewhat different health outcomes, and most studies have focused on only single chemicals. However, since essentially all humans are exposed to many different POPs, but perhaps in different relative concentrations, it is important to consider the health effects of chemical mixtures. Multiple chemicals may have additive, less than additive, or synergistic effects [13]. Because POPs are stored in adipose tissue and because the various adipose tissues of the body have somewhat different endocrine functions, it is important to know whether or not POPs distribute equally throughout all adipose tissues and ultimately to determine how levels of these chemicals influence the local adipose tissue. There is some evidence that this may occur as Arsenescu et al. [14] have reported that PCB 77 but not PCB 153 induces adipocyte differentiation and expression and release of proinflammatory cytokines.

This preliminary study of analysis of PCBs and chlorinated pesticides in various adipose tissues obtained from seven human subjects is a first attempt to determine whether the distributions of several PCB congeners and several chlorinated pesticides are the same in different adipose tissues.

\section{Materials and Methods}

Seven human subjects scheduled for elective surgery for either benign lesions or cancer provided informed consent for the surgical team to obtain blood and fat biopsies from several different fat compartments at the time of surgery for analysis of ten PCB congeners and 22 chlorinated pesticides. The study was reviewed and approved by the local Institutional Review Board. Four subjects ( 3 males and 1 female) presented with renal cell carcinoma, 1 male had a benign renal cyst, 1 male had a benign small intestinal tumor, and 1 male had prostate cancer. All subjects had preoperative CAT scans of the abdomen and pelvis, bone scans, and complete blood metabolic studies. One surgeon obtained the fat samples from all of the subjects during a laparotomy. After blood samples were drawn, the surgeon excised samples of 5 grams or greater from the subcutaneous peripheral fat as well as from one or more intra-abdominal fat stores, including visceral, retroperitoneal, and pelvic fat as well as from the kidney or prostate that was removed at surgery.

Visceral fat commonly refers to adipose tissue within the peritoneal cavity. In some subjects, visceral fat from three different locations was obtained, the mesenteric fat from around the small and large intestines, omental fat from the folds of the peritoneum that connect the stomach with other abdominal organs, and fat from the Falciform ligament that attaches part of the liver to the diaphragm and abdominal wall. Retroperitoneal fat lies posterior to the peritoneal compartment and is separated from it by the posterior peritoneum. Retroperitoneal fat surrounds the adrenal glands, pancreas, kidneys, and the great vessels as well as large lymphatic channels. The pelvic fat compartment is an inferior extension of the retroperitoneal fat and surrounds the iliac vessels, rectum, bladder, and prostate in males. The pelvic fat samples consisted of fat adjacent to 
the prostate and rectum. Figure 1 shows the location of the various fat stores as well as the major abdominal organs.

Serum and fat samples were analyzed by Accu-Chem Laboratories, Richardson, TX. PCBs and chlorinated pesticides were extracted into hexane after the addition of an internal standard $\left(2,2^{\prime}, 3,3^{\prime}, 4,5,5^{\prime}, 6\right.$-octachlorobiphenyl). The solvent was then evaporated to dryness and the sample reconstituted and analyzed on a gas chromatograph (Hewlett Packard 5890) equipped with an electron capture detector using a Hewlett Packard 5970 mass spectrometer and a DB5 capillary column. Three sets of standard references were used, one from the national Institute of Standards and Technology and two commercially available reference sets. The level of detection was $0.15 \mathrm{ng} / \mathrm{mL}$ and the level of quantitation was $0.3 \mathrm{ng} / \mathrm{mL}$. Twenty three chlorinated pesticides were measured, including hexachlorobenzene ( $\mathrm{HCB})$, endrin, $\alpha, \beta, \delta$, and $\gamma$ hexachlorocyclohexane $(\mathrm{HCH})$, heptachlor, heptachlor epoxide, $\alpha$, and $\gamma$ chlordane, oxychlordane, trans-nonachlor, endosulfan I and II, endosulfan sulfate, aldrin, dieldrin, dichlorodiphenyltrichloroethylene (DDE), dichlordiphenyltrichlorethane (DDT), dichlorodiphenyldichloroethane (DDD), methoxychlor, mirex and endrin aldehyde. Ten PCB congeners were analyzed including PCBs $47\left(2,2^{\prime}, 4,4^{\prime}\right), 105\left(2,3,3^{\prime}, 4,4^{\prime}\right), 118\left(2,3^{\prime}, 4,4^{\prime}, 5\right), 137$ $\left(2,2^{\prime}, 3,4,4^{\prime}, 5\right), 138\left(2,2^{\prime}, 3,4,4^{\prime}, 5^{\prime}\right), 153\left(2,2^{\prime} 4,4^{\prime}, 5,5^{\prime}\right), 170$ $\left(2,2^{\prime} 3,3^{\prime} 4,4^{\prime}, 5\right), 171\left(2,2^{\prime} 3,3^{\prime}, 4,4^{\prime}, 6\right), 180\left(2,2^{\prime} 3,4,4^{\prime} 5.5^{\prime}\right)$, and $183\left(2,2^{\prime} 3,4,4^{\prime}, 5^{\prime}, 6\right)$. All results are reported as wet weight values, based in part on the basis of the demonstration $[15,16]$ that lipid adjustment increases the bias in the measurement. The limits of detection were $0.3 \mathrm{ppb}$ in serum, $10 \mathrm{ppb}$ in fat and kidney cancer tissue, and $35.7 \mathrm{ppb}$ in cancerous tissue.

\section{Results}

Table 1 gives the results of pesticide levels in the various samples from the seven subjects, while Table 2 provides similar information for PCB congeners. Of the 23 pesticides monitored, none of the samples showed levels of aldrin, $\alpha$ and $\gamma$ chlordane, $\delta$ and $\gamma \mathrm{HCH}$, endosulfan II, endosulfan sulfate, DDD, DDT, endrin aldehyde, or methoxychlor above the level of quantitation, while for PCB congeners levels of PCBs 47 and 171 were not found in any tissue at concentrations above the levels of quantitation. Therefore, these substances are not included in the tables.

Figure 2(a) shows the average levels of selected pesticides in serum and various adipose tissues. Figure 2(b) shows the same data without DDE, which is present at much higher concentrations than any other pesticide. This figure clearly shows that there are some differences in the patterns, most striking in the one individual from whom a pelvic sample was obtained. The differences are less clear for those tissues for which more samples were obtained. Figure 3 shows a similar plot of PCB results.

Figure 4 shows a plot of oxychlordane concentration in visceral versus subcutaneous adipose tissues and demonstrates that there is a very close relationship with an $R^{2}$ of $0.939, P=.0003$.

\section{Discussion}

The results of this investigation show a much more complex picture for the distribution of pesticides and PCBs in various adipose tissue pools than expected. It is usually assumed that in a fasting person (all of these surgical patients were fasting), POPs will be equally distributed in all adipose tissue sites, and consequently one can obtain use serum samples to monitor body burden of lipophilic substances. While serum usually contains somewhere between $1-4 \%$ lipid, the assumption is that the POPs concentrations in the serum lipid fraction reflect all adipose tissue. In the past, results were usually reported as lipid adjusted concentrations [17] although reports that lipid-adjustment creates bias [16] have resulted in more reports of wet weight values or using serum lipids as a covariate. Unfortunately, the sensitivity used in the serum analyses in these subjects was not sufficiently sensitive so as to provide much basis for comparison, but there is valuable data from the different adipose tissue sites.

It is clear that levels of individual POPs in any one individual reflect both the degree and source of exposure, the time since that exposure occurred, genetic differences among individuals in rates of metabolism, body mass index and, if female, number of pregnancies and whether or not the child was breast fed. Most metabolism of POPs is a result of activity of cytochrome P450s, and the ability to metabolize individual POPs varies with structure and genetic susceptibility. For PCBs, for example, congeners with fewer chlorines are in general more easily metabolized than those with more chlorines [18]. Thus, an individual with major exposure in the distant past will show a congener pattern dominated by higher chlorinated congeners. However one would assume that the same pattern would be found in the various fat stores.

For PCBs, there is reasonably good correlation between serum levels and those in subcutaneous fat for GK, HM, and AS but not MS, GO, and JT. When comparing the different adipose tissues, there is a clear tendency for visceral and retroperitoneal to have a greater percentage of higher chlorinated congeners than subcutaneous fat for GK, GO and JT. However, for ML subcutaneous and visceral patterns were similar but concentrations higher than in retropertoneal fat. MS showed relatively similar patterns, but with concentrations in mesenteric fat considerably greater than in subcutaneous fat, while AS showed higher concentrations in subcutaneous fat. HM, the only subject with pelvic fat, showed relatively similar concentrations for PCBs 118, 138, and 170, but high levels of 153 in pelvic but not subcutaneous and of 180 in subcutaneous but not pelvic fat.

The patterns among the pesticides also showed surprising variability. DDE was present in the highest concentration in most samples, but was below the detection limit in subcutaneous fat in GK and JT in spite of being present at high concentrations in serum and other adipose tissues. In all other subjects, DDE concentrations were similar in the different adipose tissues. Dieldrin, heptachlor epoxide, oxychlordane, and transnonachlor were present in most adipose samples and had relatively similar distributions in 


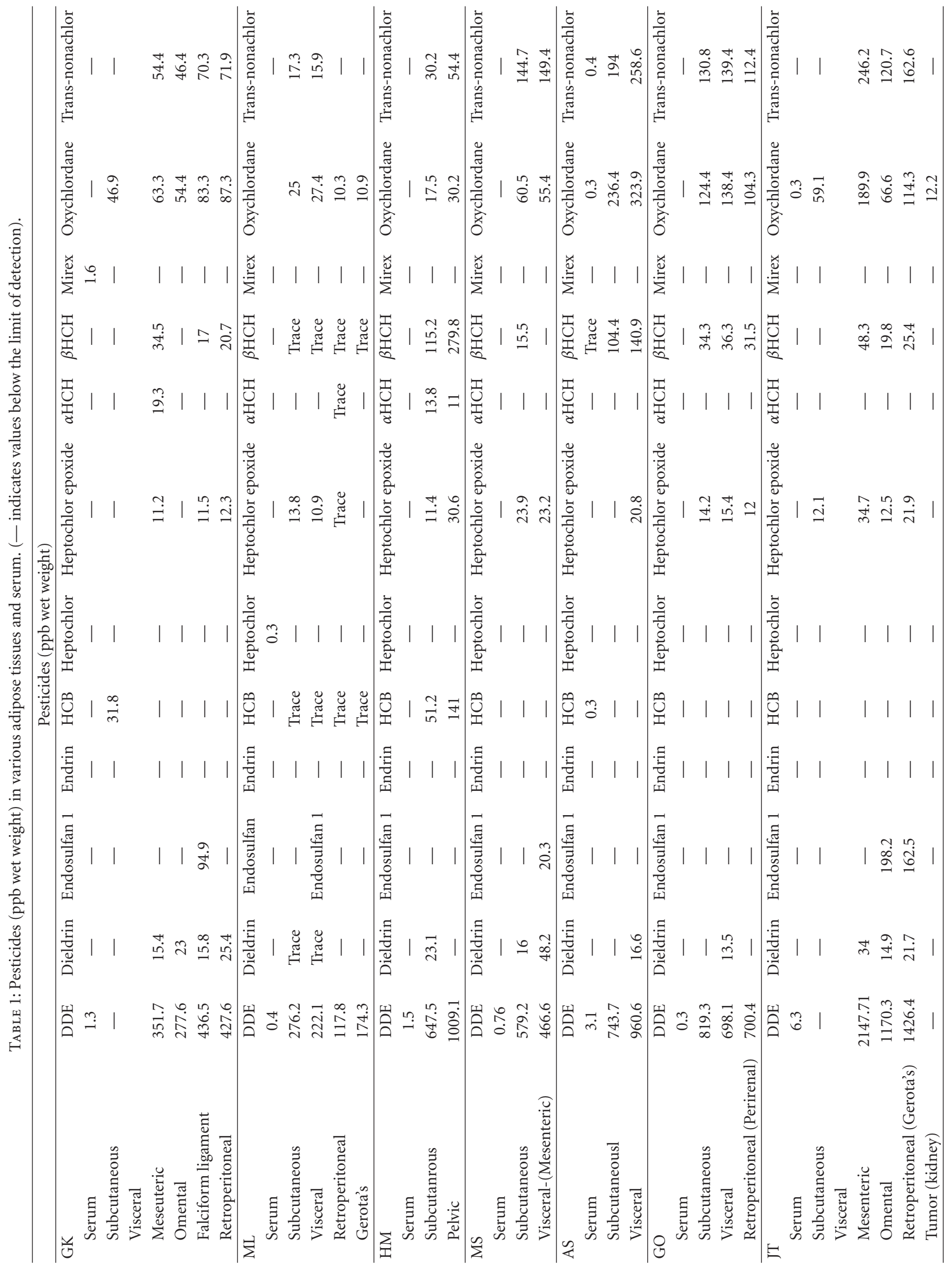


TABLE 2: PCBs in various fat compartments (ppb wet weight) (— indicates values below the limit of detection).

\begin{tabular}{|c|c|c|c|c|c|c|c|c|c|}
\hline & 105 & 118 & 137 & 138 & 153 & 170 & 180 & 183 & Total \\
\hline \multicolumn{10}{|l|}{ GK } \\
\hline Serum & - & - & - & - & 0.6 & 0.4 & 0.6 & - & 1.6 \\
\hline Subcutaneous & - & - & - & 21.5 & 39.1 & 18.8 & 32.1 & - & 111.5 \\
\hline \multicolumn{10}{|l|}{ Visceral } \\
\hline Mesenteric & - & - & - & - & - & 24.5 & 35.3 & - & 59.8 \\
\hline Omental & - & - & - & - & - & 21.5 & 33.5 & - & 55 \\
\hline Falciform ligament & - & - & - & - & - & 17.8 & 26.8 & - & 44.6 \\
\hline Retroperitoneal & - & - & - & - & - & 22 & 42.9 & - & 64.9 \\
\hline \multicolumn{10}{|l|}{ ML } \\
\hline Serum & & & & & $\operatorname{tr}$ & & & & \\
\hline Subcutaneous & - & 11.7 & - & 19.1 & 43.2 & 11.7 & 23.0 & - & 108.7 \\
\hline Visceral & - & Trace & - & 19.7 & 50.6 & Trace & - & - & 94.4 \\
\hline Retroperitoneal & - & Trace & - & Trace & 21.4 & - & - & - & 32.6 \\
\hline Gerota's & - & Trace & - & - & 34.1 & Trace & - & - & 34.1 \\
\hline \multicolumn{10}{|l|}{$\mathrm{HM}$} \\
\hline Serum & - & - & - & - & - & - & 0.4 & - & 0.4 \\
\hline Subcutaneous & - & 20.9 & - & 18.5 & - & 28 & 56.7 & - & 124.1 \\
\hline Peloic & - & 44.4 & - & 19.6 & 67.6 & 23.5 & - & - & 155.1 \\
\hline \multicolumn{10}{|l|}{ MS } \\
\hline Serum & - & - & - & - & 0.37 & - & 0.33 & - & 0.7 \\
\hline Subcutaneous & - & 30.9 & - & 16.4 & 32.7 & 12.6 & 22.3 & - & 114.9 \\
\hline Visceral-mesenteric & - & 56.4 & - & 42.3 & 92.1 & 39.2 & 60.1 & 17.4 & 317.5 \\
\hline \multicolumn{10}{|l|}{ AS } \\
\hline Serum & - & 0.3 & - & 0.4 & 0.7 & - & 0.4 & - & 1.8 \\
\hline Subcutaneous & - & 21.7 & - & 31.7 & 50.2 & 18 & 35.2 & - & 156.8 \\
\hline Visceral & - & - & - & 24.2 & - & 13.7 & 27.8 & - & 65.7 \\
\hline \multicolumn{10}{|l|}{ GO } \\
\hline Serum & - & - & - & - & 0.4 & - & 0.3 & - & 0.7 \\
\hline Subcutaneous & - & - & - & - & - & 25 & 43.7 & - & 68.7 \\
\hline Visceral & - & - & - & - & - & 28.7 & 45.3 & - & 74 \\
\hline Retroperitoneal (Perirenal) & - & - & - & - & - & 27.9 & 42.7 & - & 70.6 \\
\hline \multicolumn{10}{|l|}{ JT } \\
\hline Serum & - & 0.6 & - & 1 & 1.4 & 0.4 & 0.8 & - & 4.2 \\
\hline Subcutaneous & 13.9 & - & 12.3 & 84.8 & 158 & 38.3 & 75.9 & 18.8 & 402.3 \\
\hline \multicolumn{10}{|l|}{ Visceral } \\
\hline Mesenteric & - & - & - & - & - & 35.1 & 80.7 & - & 115.8 \\
\hline Omental & - & - & - & - & - & 39.8 & 89.7 & - & 129.5 \\
\hline Retroperitoneal (Gerota's) & - & - & - & - & - & 30.9 & 68.7 & - & 99.6 \\
\hline Tumor (kidney) & - & - & - & - & 19.2 & - & - & - & 19.2 \\
\hline
\end{tabular}

all fat stores. $\beta \mathrm{HCH}$ was present in comparable amounts in most samples that contained measureable levels, and $\alpha \mathrm{HCH}$ was found in only a few samples. Interesting $\gamma \mathrm{HCH}$ (lindane) was not detected in any sample. Mirex was found in serum at a relatively high concentration in GK, but was not present in any adipose tissue, and similar situation was found with heptachlor in ML. These results suggest a very recent exposure to these two POPs that has not yet equilibrated with adipose tissue.

When comparing general levels of PCBs to those of the pesticides, distributions were similar for ML, HM, and GO. However for AS and JT, PCBs were at higher concentrations in subcutaneous fat, but pesticides were at higher concentration in visceral and retroperitoneal fat. GK 


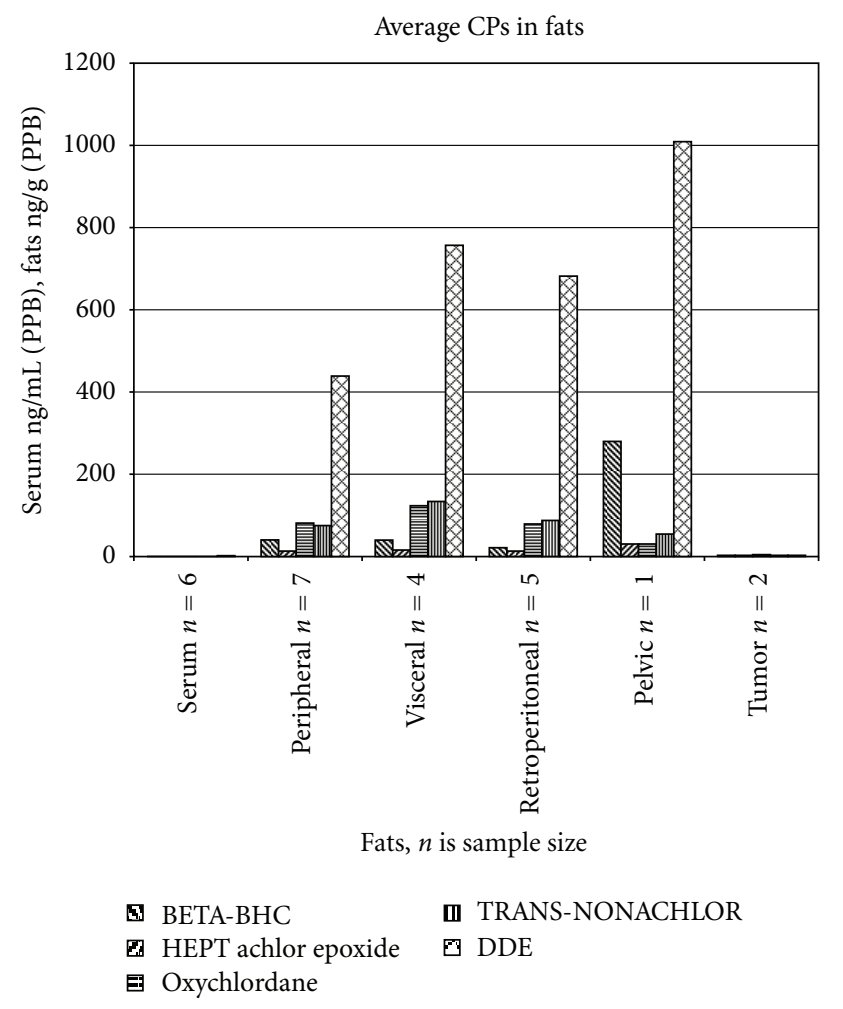

(a)

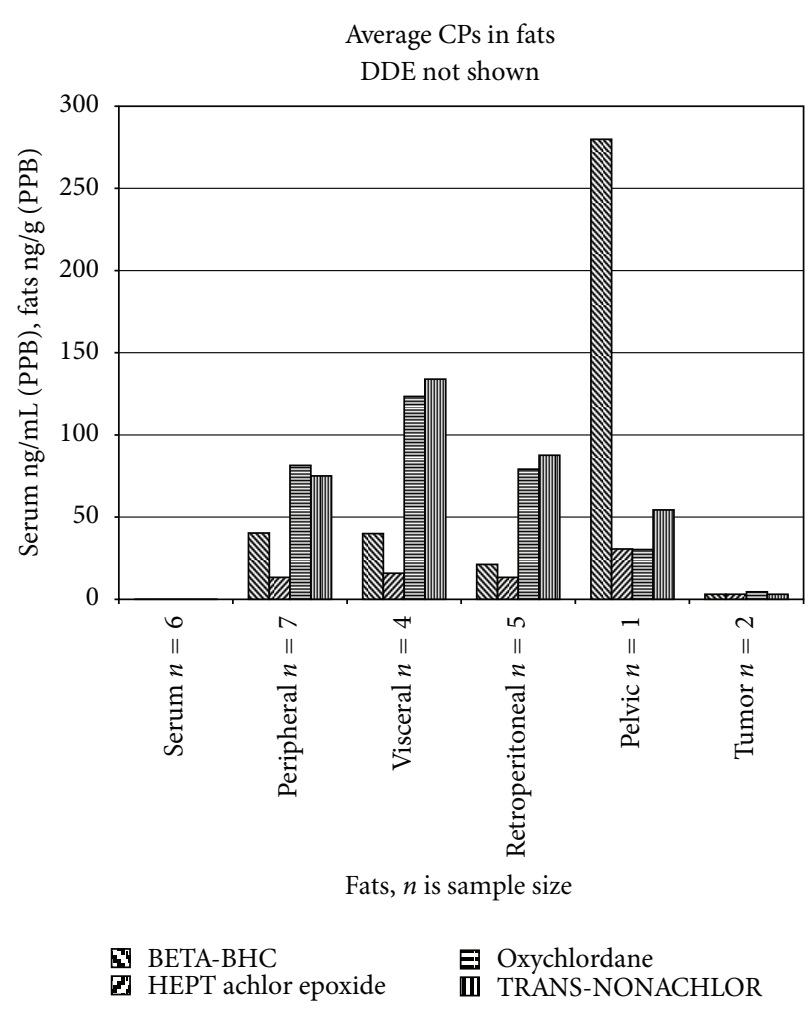

(b)

Figure 2: (a) Average levels of elevated selected Chlorinated Pesticides found in serum and fats. (b) Average levels of elevated selected Chlorinated Pesticides other than DDE found in serum and fats. The number of samples taken in the various compartments is the value of $n$.

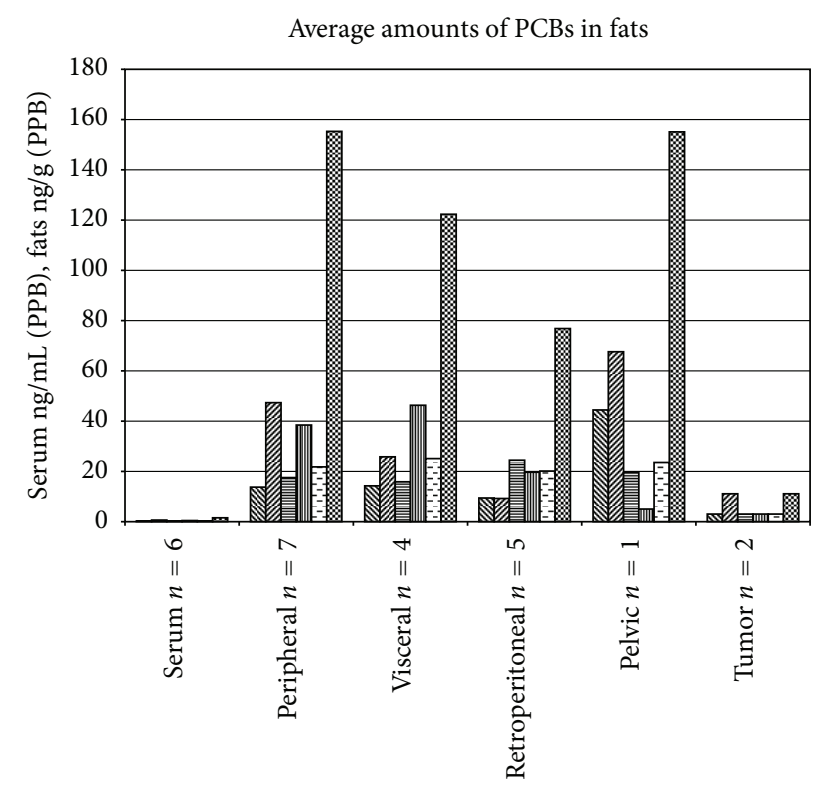

Fats, $n$ is sample size
乙 $23^{\prime} 44^{\prime} 5$ PENTA
目 $22^{\prime} 344^{\prime} 55$ HEPTA
వ $22^{\prime} 44^{\prime} 55$ HEXA
!. $22^{\prime} 3^{\prime} 44^{\prime} 5$ HEPTA
III $22^{\prime} 344^{\prime} 5$ HEXA
ब Total PCBS

FIgURe 3: Average levels of PCB and selected components found in serum and fats. The number of samples taken in the various compartments is the value of $n$. showed few pesticides in subcutaneous fat relative to other stores. For MS levels of PCBs were greater in subcutaneous than visceral fat, but levels of pesticides were approximately equal in the two stores.

Only one cancerous tissue (kidney) gave detectible levels of POPs, and it contained PCB 153 and oxychlorodane at relatively low concentrations, but no other POPs. These two POPs were present in the highest concentration in subcutaneous fat. Since the lipid content of a tumor would be expected to be significantly less than adipose tissue, the relative wet weight results are not surprising.

It is unlikely that the variable results seen in levels of both PCB and pesticides are due to chance or to faulty chemical analysis. There is always some variability in analysis of POPs, but usually this is not more than $20 \%$. The differences seen are too large to be due to experiment variability.

There are a variety of possible explanations for these surprising results. There are reports that there are large differences in the average fatty acid composition between individual subjects, as well as some differences in composition of different adipose tissue sites within subjects [19]. If this is the case, it is possible that the lipid composition of the various adipose tissue stores is reflected in different solubility of individual POPs in different depots even in the same individual. There is not a lot of information on lipid composition. Even subcutaneous fat taken from different parts of the body has been found to show between $2-10 \%$ variation $[2,20]$. There is some information suggesting that 
Oxychlordane (S) line fit plot

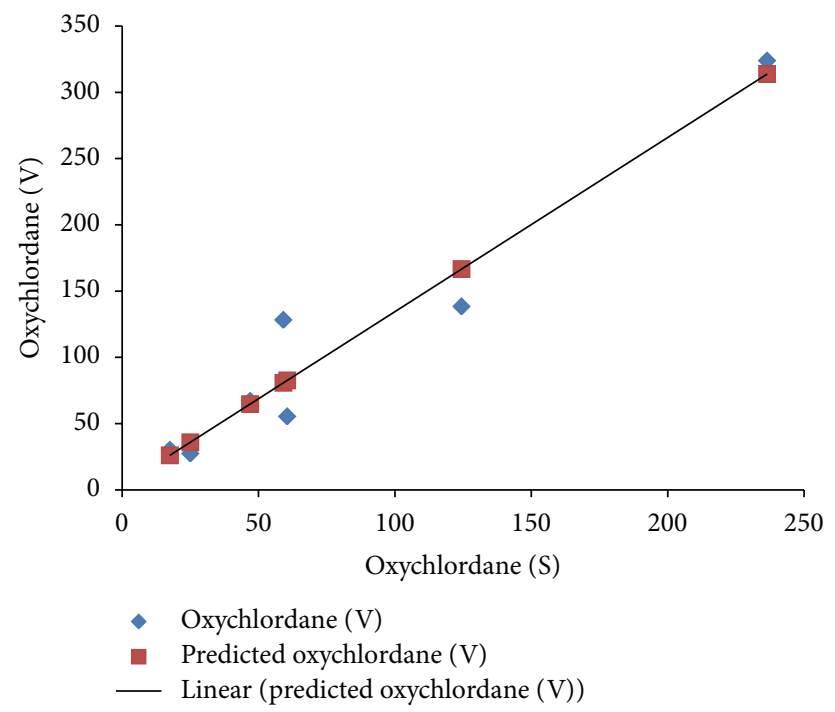

FIGURE 4: Exploring the relationship between quantities of one toxic chemical found in subcutaneous fat $(\mathrm{S})$ and either visceral fat $(\mathrm{V})$ or pelvic fat. Linear Fit: oxychlordane $(\mathrm{V})=3.0888217+1.3144289$ oxychordane $(\mathrm{S}) R^{2}=0.939, P=.0003$.

subcutaneous and visceral fats differ more, with saturated fats higher and monounsaturated fat lower in visceral than subcutaneous fat [3].

Since P450 enzymes are found in almost all cells, not just liver, it is conceivable that there is different metabolism in different fat depots. Certainly there is evidence that different depots express different endocrine factors. However, unless the POPs were bound in some fashion, it seems unlikely that even if there were differences in local metabolism that there would not be a relatively rapid redistribution.

Botella et al. [21] reported on organochlorines pesticides in serum and adipose tissue of Spanish women. They reported six POPs where serum levels correlated relatively well with those in adipose tissues, but no clear relationship with the other nine POPs. The mean adipose/serum ratios varied from 2.85 for endosulfan-ether to a high of 150.68 for DDE and 159.47 for endosulfan II. They questioned the common assumption that serum concentrations are indicative of those in adipose tissues. Our results are consistent with their observations and indicate that the same surprising relationship may also occur with different PCB congeners.

\section{Limitations}

There are major limitations to this study because of small sample size, lack of measurement of the lipid content of tissues, and the relatively low sensitivity of the analytical methods. However, the difficulty in obtaining samples and the lack of any comparable study elsewhere in light of the overall importance of the question of how different POPs distribute in different adipose tissue depots is justification for publishing these results. Replication is certainly needed to confirm the overall conclusion that POPs do not always distribute equally among various lipid compartment in the human body.

\section{Conclusions}

Contrary to expectations that patterns of various pesticides and PCB congeners were not as similar as expected when comparing levels in serum, subcutaneous, visceral, retroperitoneal, and pelvic fat. These results indicate that care should be taken when assuming that serum levels of POPs reflect patterns found in lipid stores throughout the body.

\section{References}

[1] D. Müllerová and J. Kopecký, "White adipose tissue: storage and effector site for environmental pollutants," Physiological Research, vol. 56, no. 4, pp. 375-381, 2007.

[2] L. Hodson, C. M. Skeaff, and B. A. Fielding, "Fatty acid composition of adipose tissue and blood in humans and its use as a biomarker of dietary intake," Progress in Lipid Research, vol. 47, no. 5, pp. 348-380, 2008.

[3] M. Garaulet, F. Pérez-Llamas, M. Pérez-Ayala et al., "Sitespecific differences in the fatty acid composition of abdominal adipose tissue in an obese population from a mediterranean area: relation with dietary fatty acids, plasma lipid profile, serum insulin, and central obesity," American Journal of Clinical Nutrition, vol. 74, no. 5, pp. 585-591, 2001.

[4] T. Kishino, K. Watanabe, T. Urata et al., "Visceral fat thickness in overweight men correlates with alterations in serum fatty acid composition," Clinica Chimica Acta, vol. 398, no. 1-2, pp. 57-62, 2008.

[5] B. G. Gabrielsson, J. M. Johansson, E. Jennische et al., "Depotspecific expression of fibroblast growth factors in human adipose tissue," Obesity Research, vol. 10, no. 7, pp. 608-616, 2002.

[6] A. D. Dobrian, D. C. Lieb, Q. Ma et al., "Differential expression and localization of 12/15 lipoxygenases in adipose tissue in human obese subjects," Biochemical and Biophysical Research Communications, vol. 403, no. 3-4, pp. 485-490, 2010.

[7] A. S. Yamashita, F. S. Lira, J. C. Rosa et al., "Depot-specific modulation of adipokine levels in rat adipose tissue by dietinduced obesity: the effect of aerobic training and energy restriction," Cytokine, vol. 52, no. 3, pp. 168-174, 2010.

[8] T. Christen, Y. Sheikine, V. Z. Rocha et al., "Increased glucose uptake in visceral versus subcutaneous adipose tissue revealed by PET imaging," Cardiovascular Imaging, vol. 3, no. 8, pp. 843-851, 2010.

[9] J. Fawcett, H. Sang, P. A. Permana, J. L. Levy, and W. C. Duckworth, "Insulin metabolism in human adipocytes from subcutaneous and visceral depots," Biochemical and Biophysical Research Communications, vol. 402, no. 4, pp. 762766, 2010.

[10] M. Porta, E. Puigdomènech, F. Ballester et al., "Monitoring concentrations of persistent organic pollutants in the general population: the international experience," Environment International, vol. 34, no. 4, pp. 546-561, 2008.

[11] D. O. Carpenter, "Polychlorinated biphenyls (PCBs): routes of exposure and effects on human health," Reviews on Environmental Health, vol. 21, no. 1, pp. 1-23, 2006. 
[12] B. Eskenazi, J. Chevrier, L. G. Rosas et al., "The pine river statement: human health consequences of DDT use," Environmental Health Perspectives, vol. 117, no. 9, pp. 13591367, 2009.

[13] D. O. Carpenter, K. Arcaro, and D. C. Spink, "Understanding the human health effects of chemical mixtures," Environmental Health Perspectives, vol. 110, no. 1, supplement, pp. 25-42, 2002.

[14] V. Arsenescu, R. I. Arsenescu, V. King, H. Swanson, and L. A. Cassis, "Polychlorinated biphenyl-77 induces adipocyte differentiation and proinflammatory adipokines and promotes obesity and atherosclerosis," Environmental Health Perspectives, vol. 116, no. 6, pp. 761-768, 2008.

[15] C. E. Hebert and K. A. Keenleyside, "To normalize or not to normalize? Fat is the question," Environmental Toxicology and Chemistry, vol. 14, no. 5, pp. 801-807, 1995.

[16] E. F. Schisterman, B. W. Whitcomb, G. M. Buck Louis, and T. A. Louis, "Lipid adjustment in the analysis of environmental contaminants and human health risks," Environmental Health Perspectives, vol. 113, no. 7, pp. 853-857, 2005.

[17] J. T. Bernert, W. E. Turner, D. G. Patterson, and L. L. Needham, "Calculation of serum "total lipid" concentrations for the adjustment of persistent organohalogen toxicant measurements in human samples," Chemosphere, vol. 68, no. 5, pp. 824-831, 2007.

[18] J. T. Borlakoglu and C. H. Walker, "Comparative aspects of congener specific PCB metabolism," European Journal of Drug Metabolism and Pharmacokinetics, vol. 14, no. 2, pp. 127-131, 1989.

[19] P. C. Calder, D. J. Harvey, C. M. Pond, and E. A. Newsholme, "Site-specific differences in the fatty acid composition of human adipose tissue," Lipids, vol. 27, no. 9, pp. 716-720, 1992.

[20] G. T. Malcolm, A. K. Bhattacharyya, M. Velez-Duran, M. A. Guzman, M. C. Oalmann, and J. P. Strong, "Fatty acid composition of adipose tissue in humans: differences between subcutaneous sites," American Journal of Clinical Nutrition, vol. 50, no. 2, pp. 288-291, 1989.

[21] B. Botella, J. Crespo, A. Rivas, I. Carrillo, M. F. OleaaSerrano, and N. Olea, "Exposure of women to organochlorines pesticides in Southern Spain," Environmental Research, vol. 96, no. 1, pp. 34-40, 2004. 


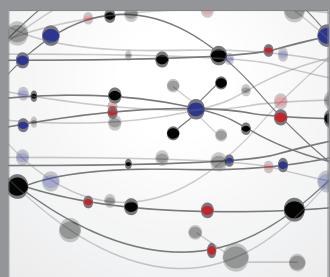

The Scientific World Journal
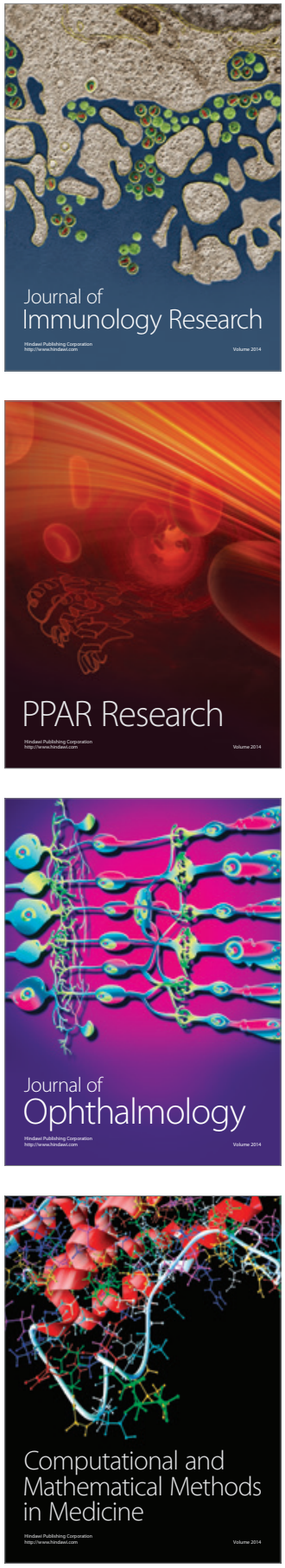

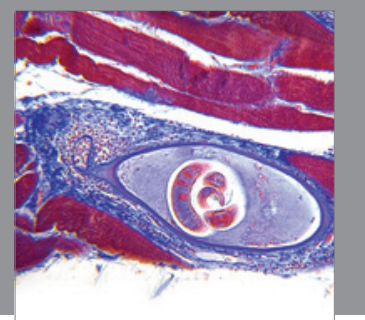

Gastroenterology

Research and Practice
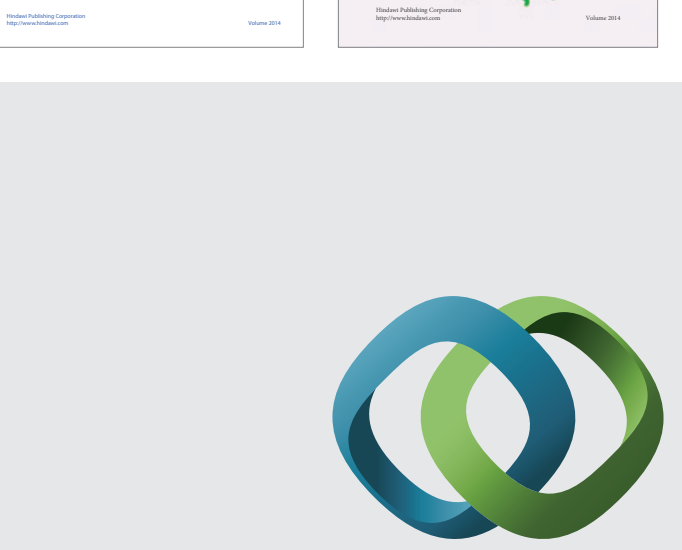

\section{Hindawi}

Submit your manuscripts at

http://www.hindawi.com
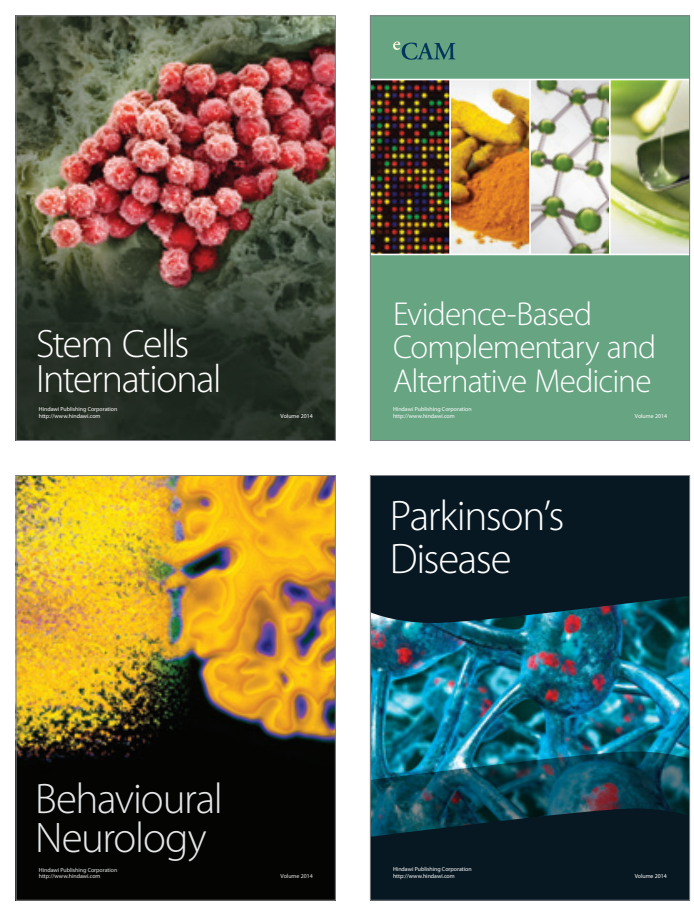

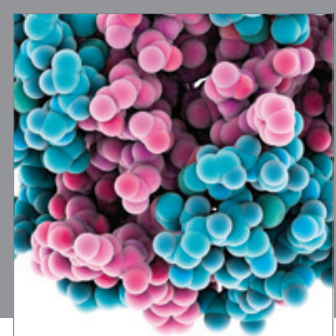

Journal of
Diabetes Research

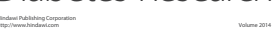

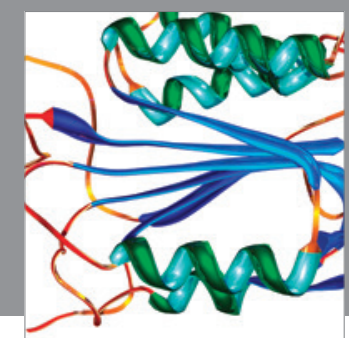

Disease Markers
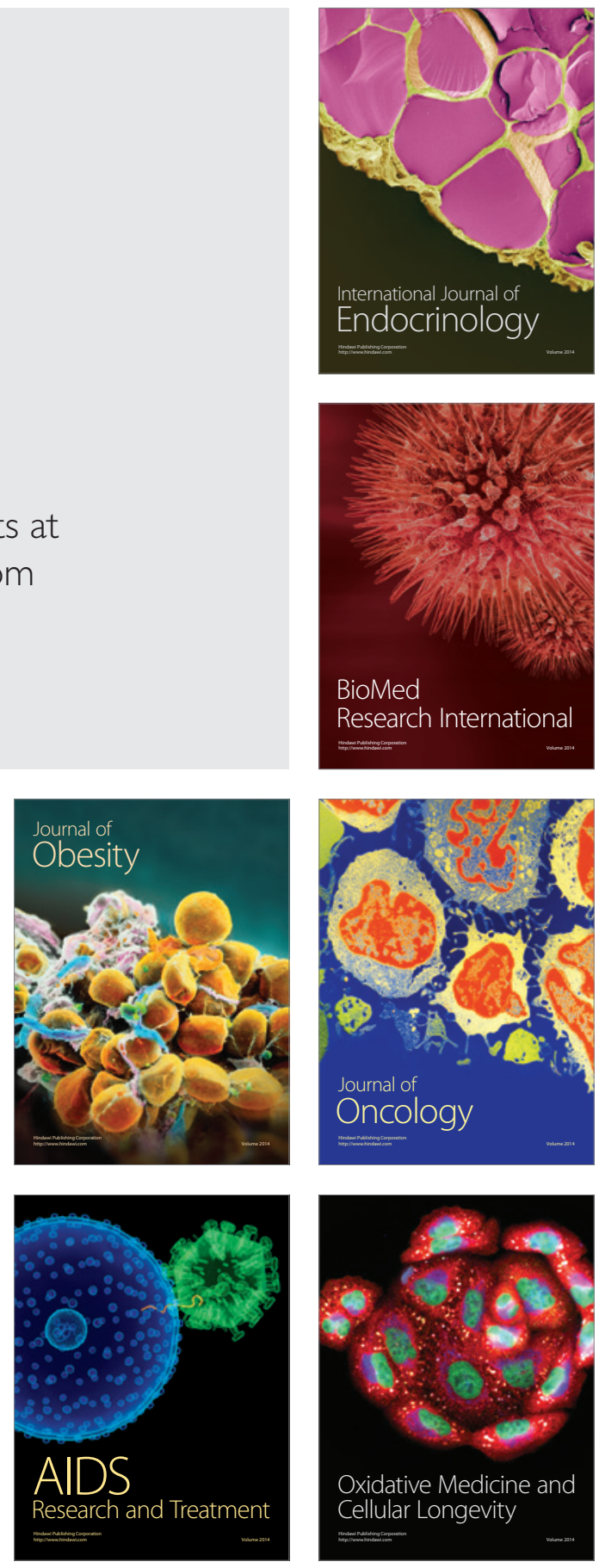